URBAN DISCHARGES AND RECEIVING WATER QUALITY IMPACTS

Edited by

J. B. ELLIS

PERGAMON PRESS

OXFORD - NEW YORK - BEIJING - FRANKFURT SÃO PAULO - SYDNEY · TOKYO · TORONTO 


\section{BIOLOGICAL ASSESSMENT OF EFFECTS OF COMBINED SEWER OVERFLOWS AND STORM WATER DISCHARGES}

L. Lijklema, R. M. M. Roijackers and J. G. M. Cuppen Water Quality Management Section, Dept. of Nature Conservation, Agricultural University, P. O. B. 8080, 6700 DD Wageningen, The Netherlands

ABSTRACT.

The biological effects of discharges from combined or separated sewer systems are difficult to assess or to predict due to variabilities in concentrations, environmental conditions, morphometry, susceptibility or organisms, on an outline of two approaches. The first approach is to generalize field site-specific conditions are shown to are presented and explained. Notably many of the biological components in the ecosystem. The second approach is to perform toxicity tests which account for the temporal and spatial scales encountered in the field and for the relevant concentration levels.

KEYWORDS

Biological effects; bio-indicators; acute toxicity; chronic toxicity; combined sewer overflows; storm water; multivariate analyses; temporal scales; spatial scales.

INTRODUCTION

Increasingly waste-waters are being treated before discharge into receiving waters. Concomitantly the relative contribution of the remalning sources of and control. Among these sources the discharges from combined and separated sewer systems are frequently important, especially near urban or industrial areas. The effects of combined sewer overflows or storm water discharges upon the receiving waters are inherently transient in nature, and it has been recognised that physical and chemical characteristics of the discharges or the effects on the level of populations of anuatic organisms or of the ecosystem Mathematical modeling has contributed significantly to the insight inte the frequency distribution of physico-chemical effects, but biological effects are still poorly amenable to prediction by modeling. Hence techniques, or rather approaches to assess harmil effects on the blota, are much in demand as the loss of function of the recelving water at least partially is related to the biological quality. 
OBJECTIVES

The objective of this paper is to discuss and illustrate how potential harmful effects of CSO's and storm water discharges can be assessed at the population and ecosystem level and predicted by appropriate tests, the use of bio-

\section{DISCUSSION OF THE PROBLEM}

various and complicated problems are encountered when this task is considered. The complexity is due to:

- the variability in time, space and intensity of the loading and the concomitant effect

checesses affecting water quality determinants and the wide range of time constants for these processes

- the complex and variable composition of the discharged polluted water the various organisms living in water or sediments in relation to their specific life cycles, habitat selection, feeding habits etc.

the seasonal and other variations in environmental conditions and the absence of any pollution to differences in morphometry, sediment and water properties, flow regimes, dilution rates and other relevant site-specific conditions.

These factors exert their influence upon the ultimate systems response in an interactive way. Some of these interactions are shown in Figure 1 in which the qualitatively. These effects are the result of the interaction of processes in the receiving water (transport, sedimentation, decay) and of response times of species or communities. The figure is far from complete but it illustrates that effects related to dynamic, high rate processes require a high frequency sampling or continuous monitoring in the vicinity of the outlet, whereas more apart from the individual storm event and on a wider spatial scale. From this it will be self-evident that biological indicators for immediate or more chronic effects should be selected on the basis of their generation time as a first criterion.

Further it will be clear that differences in flow conditions will dominate over other factors. This is already true for non-polluted systems: running waters harbour quite different communities than stagnant or semi-stagnant systens. Also the recoly dif

Biological effects that can be expected to occur include:
- wash out of organisms with the water and scour of organisms out of the sediments (comparable to catastrophic drift);

- reduction of DO resulting in die off of organisms;

- turbidity, reducing primary productivity, but also

The duration and level of the adverse concentrations may lead to acute toxicity effects, but generally chronic effects due to prolonged exposure at low concentrations of micropollutants are more likely to occur than acute consequences. Low oxygen concentrations, however, can be expected shortly after an overflow event and can be very harmful for fish, particularly when deficits has been shown to have comparable effects. This has resulted in recommended standards for DO as a function of exposure time in Denmark (Hvitved-Jacobsen, 1986), which is probably too sophisticated for practical management. More important is the concept to relate standards to recurrence time as proposed by the same author. This concept is important in relation with the generation tine of organisos to becon geccetable.

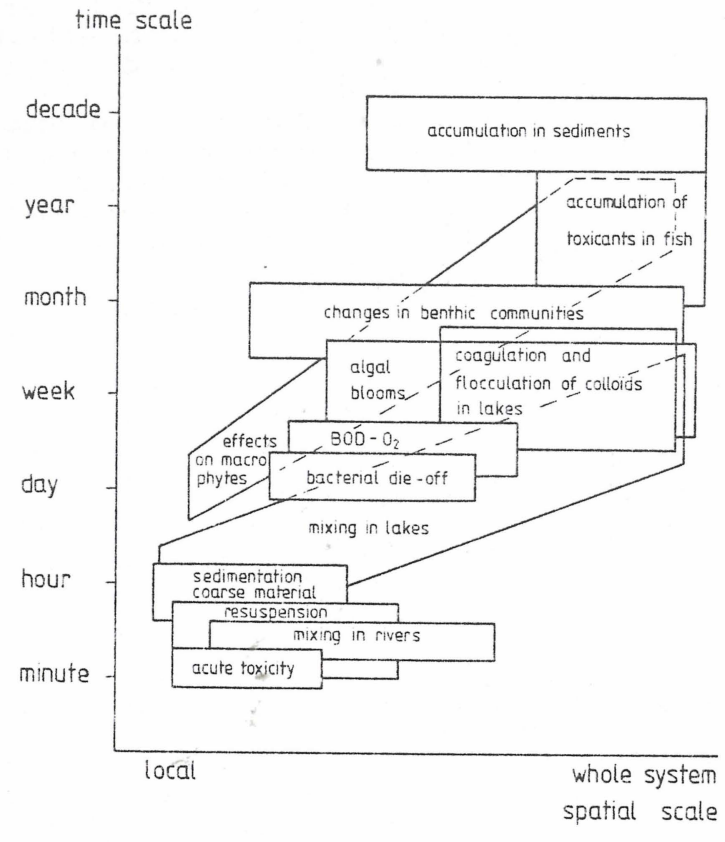

Figure 1. Relation between the rates of processes and the
the effects (from: Aalderink and Lijklema, 1985).

Ideally, impact studies would require controls in both time and space (Green, 1978). This is so because evidence for an effect must be based on changes that occurred in the test area, but not in the control area. Such a set up would already occurred near the outlet, uniess a new discharge is being studied.

As to the choice of indicator or test organisms, it will be evident from inspection of Figure 1 that more permanent effects can be expected to show up accumulate and adverse conditions are more permanent. short term effects to show up predominantly in short living organisms in the water phase. would with their complex interactions in the food web and mobile character, would exhibit both acute and chronic effects. It should be noted that effects on the may rom in in metabolic rates or yields integration: population dynamics (Halbach, 1984). Extrapolation of this observation leads to the conclusion that no-effect levels will be even lower for the ecosystem. Hence interpretation of field data or test results on the level of isolated organisms or species should be made with caution.

TWO APPROACHES

Considering the variability in time, space, effluent composition, the sitespecific conditions and the lack of detailed knowledge of the interacting physical, che uniform, simple and unbiassed on the bi lo predict harmful effects from two different sides, each with their limitations but can be more or less supplementary.

$A W P C-D$ 
The first approach: Evaluation and generalization of field experiences. organism, including spatial and temporal gradients and different combination of sewer system, morphometry of receiving water, season etc. a general insight can be obtained intothe extent and duration from to be expected at a speciflc site can be lnfe and acceptable. Alternatively the by analogy and compared to what is dence framework can be assessed and compared position or anges to be expected from management measures indicated. The task involves the evaluation and interpretation of large data sets and the use of techniques that allow the discrimination between cause-effect relationships. such an analysis also may indicate which for impact analysis.

The second approach: Direct tests with indicator organisms. effuent and/or the This approach bio-assays in which the relative potency of a solution is compared with the effect of a standard solution (such as the assays used in eutrophication studies) and, more important here, toxicity tis being measured. Both approaches will be discussed.

Evaluation and generalization of field experiences. the functioning and/or structure of the biological components. However, generallzation of observed effectsucture among (communities of) organisms due differences in fond development patterns. These patterns are to distributionined by master factors as, for instance, seasonality, current velocity, salinity, morphometry, acidity and sediment composition.

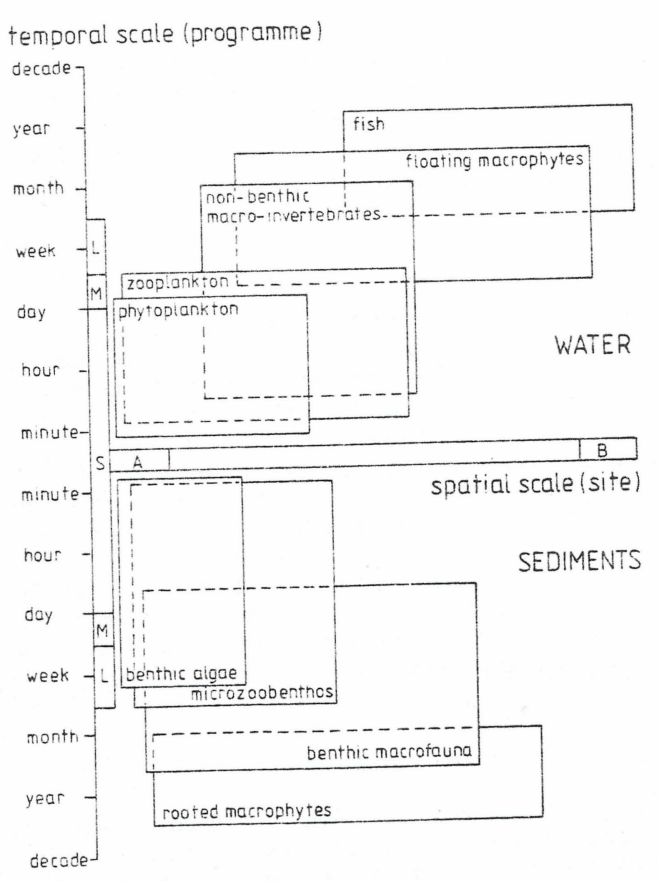
various biompling programm various bite.
An extensive study from 1985 to 1987 included a wide variety of localities throughout The vetherlands ( $>50)$, selected on the basis of type of sewer system and receiving water. At each locality three sampling sites have bee selected:

(the overflow:

site B: at some distance of the overflow, but within its sphere of influence; influenced by the overflow. As effects of overflows on biologicai objects are expected to be reflected in and their habitat (free-floating or planktonic the type or organism studied sampling programe included:

programme (hort): immediately after an overflow event;

programe M(edium): one to four days later:

programme $\mathrm{L}$ (ong): one or two weeks after an overflow event;

programme $B$ (background): at least one month after an overflow event.

Depending on morphometry and other characteristics of the sampling sites (habitat selection) and on the life-cycle of the organisms, the following biological objects have been studied: phytoplankton (S \& M), microfaun invertebrates ( $L \& B$ ) and macroflora (B).
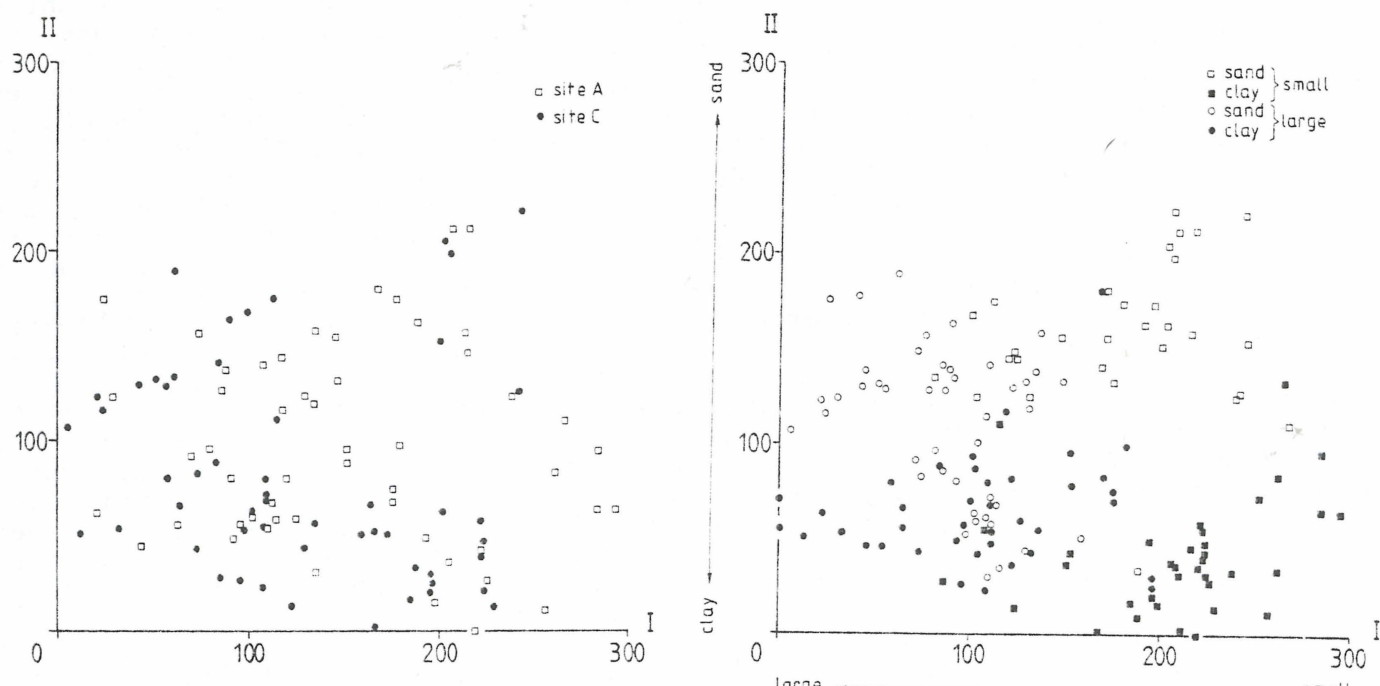

Figure $3 a$ (left). Ordination diagram of sampling sites $A$ and $C$ on the basis of Figure $3 b$ (right). Ordination diagram of sampling sites $A, B$ and $C$ on the basis of macro-invertebrate species composition and abundance.

Clustering (TWINSPAN) and ordination (DECORANA) of the sampling sites on the basis of similarity in species composition and abundance proved to be useful above. only the results of the macro-inwertebretes investigations are used here to illustrate this. Figure 3 a shows a diagram of the $\mathrm{A}$ and $\mathrm{C}$ sampling sites in (semi-) stagnant waters, ordinated on the basis of their macrofauna species composition and abundance. In contrast to expectations, the $\mathrm{A}$ and $\mathrm{C}$ sites are distributed randomly throughout the plot, indicating that the ordination of the sites (including the $B$ sites) is not determined primarily by the of all the sites is largely determined by the size of the receiving water body (first principal axis) and the sediment composition (second principal axis). So the influence of overflows on macro-invertebrates is only of secondary importance. As site-specific conditions (morphometry and sediment composition) are so important, harmful effects can only be detected when receiving waters 
In general, the smaller or more isolated the water body, the more pronounced differences in species composition between the sites are. In large closed there the first effects will be found. As far as toxic components are not released or of secondary importance, traditional biological assessment methods can also be used (Pantle and Buck, 1955; Woodiwiss, 1964; Moller Pillot, 1971; Sládececk, 1973; Gardeniers and Tolkamp, 1976). These methods are based upon (groups of) species indicating the saprobic level, traditionally assoc biological oxygen demand and ammonium.

作 of the water body with species. If the water body is isolated and difficult to access inoculation is prevented. Soil conditions will deteriorate furthe after each new event. Due to mineralization of organic matter oxygen As indicated previously, the different biological components in an ecosystem will react differently upon external changes. To illustrate the differences in selected to study the effects of overflows upon the different biological components of the system. A pond frequently disturbed by overflows (Loenen) has been studied intensively during one year (1984) using a fortnightly sampling programme. A non-disturbed pond in the neighbourhood has been used as reference (Apeidoorn). Results of these investigations have been published by willemsen and cuppen (1986) and by Roljackers and Ebbeng (1986). Effects on induced, e.g. passive transportation by the incoming water masses or changes in turbidity (algae). The recurrent overflows in the detention pond prevented maturation of the ecosystem and community structure was minimal. The communities of epiphytic diatoms in particular showed an architecture accomodated to the resistance of flushing, whereas the epiphytic diatom communities in the reference pond was possible, but fluctuations through time were barely detected (Figure 4: top). Phytoplankton reacted mainly upon changes in light climate as nutrients were never limiting. After an overflow event phytoplankton and turbidity causing colloidal matter was flushed and the water mass became very transparent for a few days. Due to the higher irradiance level phytoplankton turnover rate. phytoplankton was not suitable to indicate saprobic degrees (Figure $4:$ bottom). Zooplankton clearly reacted on water movements and input of organic matter (Figure 4: middle). In the case of zooplankton and macroinvertebrates the importance of inoculation from the shore vegetation (a temporary refuge) was clearly indicated. From this study it was clear that effects of overflow everts, whereas algae and micro-invertebrates the long term term effects (Figure 2).

On the basis of the above-mentioned studies a suitable biological component can be selected for field observations, depending on the type of water and indicator organisms that can be used in laboratory studies among which bioassays are most popular. In future, however, more attention should be paid to larger scale laboratory experlments, in which natural situations are reflected betcer and tool in testing the effects of pollutants under natural conditions.

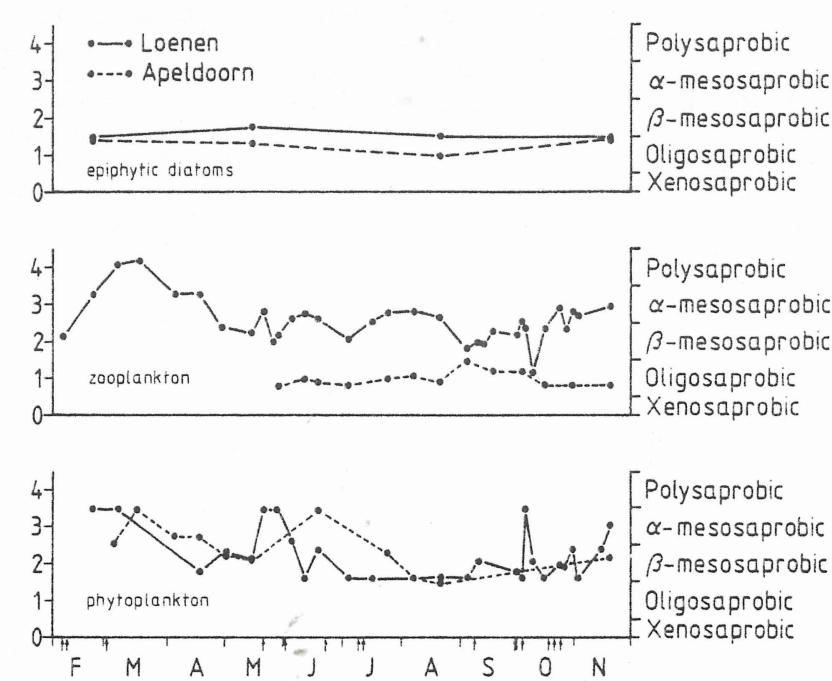

Figure 4. The saprobic level according to sládecek (1973) for a pond in Loenen (from: Roijackers and Ebbeng, 1986).

\section{TOXICITY TESTS, BIO-ASSAYS}

In order to be relevant for field conditions toxicity tests and bio-assays should represent as well as possible:

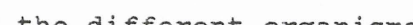

b) the (variations in) concentrations of pollutants and concomitant physico-

tests do not take into account time-concentration efined time period. In an organism is exposed to a fixed concentration for a degradation, dispersion, sedimentation etc. The rate of decrease will be dhe waste-waters. This is difficult

Exposure time.

conditions of removal rates of pollutants and the fading away of adverse take into account the flow conditions in the receiving water and the mobility of the organism used as a bio-indicator. In running waters the exposure time will be short for mobile organisms (fish), somewhat longer for passive for aquatic weeds. In with the water (phytoplankton, zooplankton) and short time will be longer, especially for sessile organisms, while exposure time is long for all organisms in closed water bodies (ponds, lakes). In the sediments the exposure time will be long, except for readily degradable matter.

From the above it follows that tests on organisms living in the water phase tests in which the acute toxicity tests. Such tests are frequently mortality preset, fixed time of exposure. This concentration causing $50 \%$ mortality has the least variability in the concentration-response curve. The exposure time is generally 24,48 or $96 \mathrm{~h}$. Other effects are sometimes measured instead of mortallty, such as suppression of growth in algae, lmmobility or loss of . The expression EC50 is used in such cases: median 
Although toxicologists generally prefer flow-through test conditions, a static test may be more representative for overflows from sewer systems. In such tests the solution (effluent) is added to the dilution water any change o water during the test. This exposure system allows degradation, build up of metabolic products, adsorption, volatilization and depletion of oxygen to standardize of particular interest is the probability of synergistic effects with low oxygen concentrations. For instance the LC50 for $96 \mathrm{~h}$ exposure o rainbow trout has been shown to decrease with decreasing Do concentration (Thurston, 1981, in Russo, 1985).

For CSO's the recurrence time is generally long. This means that the fate of organisms with a short life cycle is not very interesting and mainly higher organisms should be tested. For isolated systems where recolonization is a problem this is not necessarily true. For storm water discharges the recurrence time is much shorter, hence short living organisms may become lmp algae stimulation of growth may occur as well as a consequence of nutrient addition. A bio-assay may then indicate the potential for growth stimulation, but a chemical analysis of nitrogen and phosphate may be adequate.

As discharges generally occur during all seasons, it seems appropriate to pay special attention to the early life stages, eggs etc., because these tend to be the most senisis.
mechanism. organisms living in sediments are exposed to more prolonged harmful conditions. Except for readily biodegradable and volatile compounds, the pollutants associated with settling particles will exert their influence on
benthic organisms for periods which well may exceed the recurrence time of benthic organisms for periods which well may exceed the recurrence time of
overflow events. Hence chronic tests seem appropriate. A major problem with chronic toxicity tests in general is that they are expensive. In the case of CSO or storm water it is also difficult to have the disposal of a supply of test solution of constant and well defined composition. These are reasons to consider methods of extrapolating acute toxicity tests. For this purpose the concept of an application factor (AF) has been developed, which is the also the range in which it lies: No Observed Effect concentration (NOEC) to The assumption is that the ratio between the chronic test values (MATC, NOEC and LOEC) and the acute toxicity value LC5O is relatively independent of the species tested for a specific chemical (Rand and Petrocelli, 1985). As a consequence the tests need not to be performed with long living organisms for which the test period may be as long as one year. Instead the tests can be maly an acute test with other relevant species is needed. For application to benthic organisms exposed to quite different substrates than Daphnia this comparison fails of course. Furthermore no information regarding the independency of $\mathrm{AF}$ for complex effluents is known to the authors. Extrapolation of Early Life Stage tests to MATC has proven to be succesful in many cases (MCKim, 1985) for individual toxicants and some support is ava tests. Hence this direction seems to be promising for further development. A major problem may be that the concentration in effluents is insufficient to assess the LC50 value properly, whereas dilution in the receiving water is not such that chronic elfects can be excluded off-hand.

concentration of effluents will affect their physico-chemical properties.

Concentration effects.

- the variations in composition of the effluent

- the variations in volume of the discharge and hence the initial dilution in the receiving water water.
The maximum concentration in the receiving water will be that of the non diluted effluent as it may push aside stagnant water or is mixed wit distance the concentrations will decrease. There is a distribution in effect to be expected related to the distribution in concentrations and exposure times. As stated in the previous section, the decreasing concentrations in time due to reactions may be simulated by performing stationary tests. dilution series. In each of the individual test solutions also the temporal effect of degradation etc. will occur to a certain extent.

Generally the maximum toxicity will be the most important quantity to assess. For this it may be necessary to know the seasonal variation in flow of the receiving water and the most sensitive life stage of the species to be tested. Usuly the flow conditions in the (late) summer. Low flow and high temperature will frequently go together and may induce low Do levels. This all accentuates the local, site-specific conditions.

The treatment of the variation in effluent composition and strength necessarily must be simple. The -more toxic conditions deserve most attention, but it is not practical to store effluents and perform tests with the samples with the hish effects to the higher concentration range on the basis of a distribution of concentrations. This distribution may follow from chemical analyses of greater number of samples. Extrapolation to the geometric mean of the highest quartile of concentrations might be a reasonable approach. Alternatively model results can be used but for quality the results are still rather poor. O variation in concentration will be different for each variable. So the extrapolation suggested should be applied to the variable(s) which is (are)
suspected to dominate the effects. This can be based on the results of chemical analyses and data on the toxicity of individual chemicals.

Results of acute toxiclty tests performed according to the generai guidelines chemicals studied the chronic toxic con to acute toxicity concentration. Macek (1985) reports that the limited data on complex waste waters and treated industrial effluents provide evidence that an application factor in the range of $0.05-0.1$ would be a reasonably good

\section{Field testing.}

Although on-site testing in principle would be more informative and realistic in several respects, it is practically difficult due to the stochastic nature of overflows. For a limited number of organisins however, comparative tests in the test organism can be placed upstream and downstream of a discharge. For a arrangement can be very useful. Sessile plants and animals and (caged) fish can be used.

\section{MATHEMATICAL MODELS}

These will be discussed in other contributions in this volume. Here it suffices to state that, although ecological effects cannot yet be predicted effects of specific toxicants can be obtained from mathematical models. The complement other information and help to organize studies and the analysis of their results. In this respect the models TOXIWASP and EXAMS should be
mentioned, see e.g. Mulkey et al. (1986). 
REFERENCES

Aalderink, R.H. and Lijklema, L. (1985). Water quality effects in surface waters receiving storm water discharges. In: water in urban areas. TNO TNO, The Hague, 143-159.Green, R.H Proceedlngs and Information No. 33; and analysis. In:

Biological data in water pollution assessment: quantitative and Statistical analysis. ASTM STP 652 , K.L.Dickson, John Cairns, Jr and ardeniers, J.J.P. (Eds.) American Society for Testing and Materials, 3-28. lowland streams in the Achterhoek (The Netherlands) by means of a system
for the assessment of water quality based on macro-invertebrates. Nature Conservation Department Agricultural University, Wageningen, Informations

No. 143.
Halbach, U. (1984). Population dynamics of rotifers and its consequences for
ecotoxicology. Hydrobiologia, itved Jacobsen, $\frac{\text { Hydrobiologia, }}{\text { T. }}$ (1986). Conventional $79-96$

waters. In: Urban Runeff pollutional pollutant impacts on receiving Desbordes (Eds.) NATO ASI Series, Series ${ }^{2}$ Vol.10. Marsalek and $M$. Desbordes $345-421$.

Kersting, K. (1984a). Development and use of an aquatic micro-ecosystem as a test system for toxic substances. Properties of an aquatic microecosystem. IV. Int. Revue ges. Hydrobio1. ' $\frac{69}{2}$ : 567-607.

strain a system parameter for the analysis of toxic stress in (micro-) ecosystems. Ecological Bulletins, $3 \epsilon$, $150-153$.

Macek, K.J. (1985). Effluent evaluation. In: Fundamentals of Aquatic Toxicology, G.M.Rand and S.R.Petrocelli (Eds.). Hemisphere Publishing Corp., washington, 636-651.McKim, J.M. (1985). Early life stage toxicity tests. In: Fundamentals of Aquatic Toxicology, G.M.Rand and S.R.

Moller Pillot, H.K.M. (1971). Faunistische beoordeling van de verontreiniging
in laaglandbeken. Thesis

Mulkey, L.A., Ambrose, R.B. and Barnwell, T.O. (1986). Aquatic fate an transport modeling techniques for predicting environmental exposure to organic pesticides and other toxicants - A comparative study. In: Urba Runofe pollution, H.C. Tovi Vor

ntle, E and Buck, Hi. (1955). Die biologische überwachung der Gewässer und

and die Darstellung der Ergebnisse. $\frac{\text { Gas- und Wasserfach, }}{\text { (1956) }}, 604$.

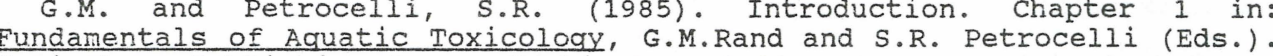
(a)

(1986). Structure and functioning of planktonic and epiphytic communities in a pond receiving combined sewe overflows. In: Urban storm water quality and effects upon receiving waters. TNO Committee on Hydrological Research; Proceedings and Information No. 36; TNO, The Hague, 297-310. Russo, R.C. (1985). Ammonia, Nitrite and Nitrate. In: Fundamentals
of Aquatic Toxicology, G.M.Rand and S.R.Petrocelli (Eds.). Hemisphere

water guality from the biological point of

Willemsen, $\frac{\text { Arch. Hydrobiol. /Erg. Limnol. }}{\text { G.D. and Cuppen, J.G.M. }}\left(\frac{7}{1986)}, 128\right.$ pp. Effects of combined sewer overflows on the macro-invertebrate communities in a detention pond. In: Urban storm water quality and effects upon receiving waters. TNO TNo, The Hague, $283-29$

Woodiwiss, the Trent River Board. Chem. Ind., 14, 443-447. 